\title{
Leaching of Gold from the Waste Mobile Phone Printed Circuit Boards (PCBs) with Ammonium Thiosulphate
}

\author{
Abhishek Tripathi ${ }^{1}$, Manoj Kumar ${ }^{2, *}$, D. C. Sau ${ }^{2}$, Archana Agrawal ${ }^{2}$, Sanchita Chakravarty ${ }^{3}$, \\ T. R. Mankhand ${ }^{1}$ \\ ${ }^{1}$ Department of Metallurgical Engineering, Institute of Technology, Banaras Hindu University, 221005, Varanasi \\ ${ }^{2}$ MEF Division, CSIR- National Metallurgical Laboratory (NML), 831007, Jamshedpur \\ ${ }^{3}$ Analytical Chemistry Centre, CSIR-National Metallurgical Laboratory, 831007, Jamshedpur \\ mkr1971@gmail.com
}

\begin{abstract}
The rapid growth in the use of electronic equipments, combined with early obsolescence has contributed enormously to the generation of large quantity of electronic (e) waste. One such e-waste, the mobile phone printed circuit boards (PCBs) contain various precious metals which can be extracted by different hydrometallurgical routes. The present work deals with the recovery of gold using ammonium thiosulfate as a leaching agent from waste mobile PCBs containing $0.021 \% \mathrm{Au}, 0.1 \% \mathrm{Ag}, 56.68 \% \mathrm{Cu}, 1.61 \% \mathrm{Ca}, 1.42 \% \mathrm{Al}, 1.40 \% \mathrm{Sn}, 0.24 \% \mathrm{Fe}, 0.22 \% \mathrm{Zn}, 0.01 \% \mathrm{Pd}$ etc.. The cutting granules of $0.5-3.0 \mathrm{~mm}$ PCBs were used for leaching in a $500 \mathrm{~mL}$ glass beaker in open atmosphere. The effect of various parameters viz. ammonium thiosulfate concentration, copper sulfate concentration, $\mathrm{pH}$ and pulp density was studied. A leaching of $56.7 \%$ gold was obtained under the optimum condition of $0.1 \mathrm{M}$ ammonium thiosulfate, $40 \mathrm{mM}$ copper sulfate, $\mathrm{pH}$ : $10-10.5$, pulp density: $10 \mathrm{~g} / \mathrm{L}$ at room temperature and stirring speed of $250 \mathrm{rpm}$ in $8 \mathrm{~h}$ duration. The maximum leaching of gold in the $\mathrm{pH}$ range 10-10.5 may be attributed to the higher stability of the ammonium thiosulfate. The decomposition of ammonium thiosulfate in the different $\mathrm{pH}$ ranges was chemically analysed by iodometric method. The ammonium thiosulfate contents in the leach liquors were in agreement with the quantity of gold leached in the respective $\mathrm{pH}$ ranges. In this process the copper sulfate worked as a catalyst. The experiment conducted with complete PCBs scrap exhibited a maximum leaching of $78.8 \%$ gold at the above optimised condition.
\end{abstract}

Keywords Waste Mobile Phone, Printed Circuit Boards (Pcbs), Ammonium Thiosulfate Leaching, Gold Leaching

\section{Introduction}

In recent years there has been tremendous growth in the use of many information and communication technology products, such as mobile phones, computers, television sets etc. The rapid advent of changing technology makes early obsolescence of these electronic equipments. This has contributed enormously to the large quantity of the electronic waste (e-waste) generated around the world. The United Nations estimates that collectively world is generating some 20-50 million tons of e-waste every year ${ }^{1}$.The latest report by $\mathrm{UN}^{2}$ predicts that by 2020 , e-waste from old computers will jump 5 times in India compared to 2007. It also estimates that by the same year e-waste discharge from mobile phones in India will be 18 times higher than 2007. There are also growing concern about the e-waste generated in developed countries due to the lack of infrastructure for environmentally sound management of e-waste. The e-waste from such

* Corresponding author:

mkr1971@gmail.com (Manoj Kumar)

Published online at http://journal.sapub.org/ijmee

Copyright (C) 2012 Scientific \& Academic Publishing. All Rights Reserved equipments contain many toxic elements such as lead, mercury, cadmium, nickel, chromium etc which has an adverse impact on our environment. Moreover, the e-waste also contains many valuable metals such as gold, silver, platinum, palladium etc. Therefore recycling and metal recovery from e-waste is required to protect the environment vis-à-vis resource conservation. Treatment of e-waste has been done mainly by the pyrometallurgical processes but due to emission of noxious gases and low recovery of metals, researchers are looking towards the hydrometallurgical processes because this route is easily controlled and better predictable.

Conventional recovery of gold was done by the cyanidation, a 100 years old leaching process for the recovery of the gold and other precious metals from the complex ores ${ }^{3}$. But due to toxicity of the cyanide, its use in this process has been prohibited in many countries. Thiourea is a non-cyanide lixiviant for gold leaching which efficiently recovers gold ${ }^{3}$ but this is not an economical route for the gold leaching due to its high consumption and cost. Thiosulfate leaching to recover gold from ores is known for several decades but extensive researches have been started only for the past two decades ${ }^{4}$. The process of recovering gold from mobile phone PCBs is an innovative approach to obtain the precious metals. 
Literature reveals that only limited studies have been carried out to recover the metals from waste mobile phone PCBs. Ammonium thiosulfate $\left[\left(\mathrm{NH}_{4}\right)_{2} \mathrm{~S}_{2} \mathrm{O}_{3}\right]$ is a leachant which is non-toxic as well as economical. It works to stabilize gold as anionic complex which is mainly accountable for the gold recovery. Thiosulfate leaching has many advantages over the cyanidation process including higher leaching rates and less interference from foreign ions.

\section{Theoretical Consideration}

Thiosulfate when combines with the gold, a complex formation occurs i.e. aurothiosulfate $\left[\mathrm{Au}\left(\mathrm{S}_{2} \mathrm{O}_{3}\right)_{2}{ }^{3-}\right]$ which is accountable for the gold recovery as shown in equation (1). Copper sulfate was used as catalyst and oxidizing agent in the solution which forms a stable cupric tetra amine complex (eqn. 2) when reacts with ammonia, ${ }^{5,6}$, which stabilizes the aurothiosulfate complex.

$$
\begin{aligned}
4 \mathrm{Au}+8 \mathrm{~S}_{2} \mathrm{O}_{3}{ }^{2-}+\mathrm{O}_{2}+2 \mathrm{H}_{2} \mathrm{O} \longrightarrow 4 \mathrm{Au}\left(\mathrm{S}_{2} \mathrm{O}_{3}\right)_{2}{ }^{3-}+4 \mathrm{OH}^{-} \\
\mathrm{Au}+5 \mathrm{~S}_{2} \mathrm{O}_{3}{ }^{2-}+\mathrm{Cu}\left(\mathrm{NH}_{3}\right)_{4}{ }^{2+} \\
\longrightarrow \mathrm{Au}\left(\mathrm{S}_{2} \mathrm{O}_{3}\right)_{2}{ }^{3-}+4 \mathrm{NH}_{3}+\mathrm{Cu}\left(\mathrm{S}_{2} \mathrm{O}_{3}\right)_{3}{ }^{5-}
\end{aligned}
$$

The cupric tetra-amine complex ions get regenerated by reaction between dissolved oxygen and $\mathrm{Cu}\left(\mathrm{S}_{2} \mathrm{O}_{3}\right)_{3}{ }^{5-}$ as per reaction (3)

$$
\begin{aligned}
& \mathrm{Cu}\left(\mathrm{S}_{2} \mathrm{O}_{3}\right)_{3}{ }^{5-}+4 \mathrm{NH}_{3}+1 / 4 \mathrm{O}_{2}+1 / 2 \mathrm{H}_{2} \mathrm{O} \longrightarrow \\
& \mathrm{Cu}\left(\mathrm{NH}_{3}\right)_{4}{ }^{2+}+3 \mathrm{~S}_{2} \mathrm{O}_{3}{ }^{2-}+\mathrm{OH}^{-}
\end{aligned}
$$

\section{Experimental}

\subsection{Raw Materials}

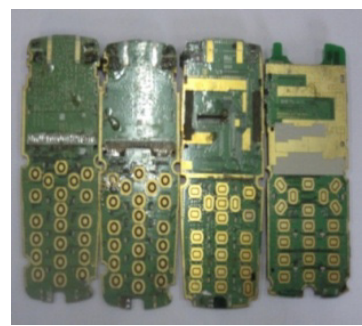

Figure 1. Mobile PCBs

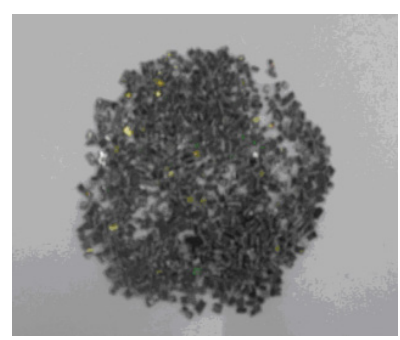

Figure 2. Granules of mobile PCB after cutting

Table 1. Chemical analysis of metals present in the mobile PCBs

\begin{tabular}{|c|c|c|c|}
\hline Elements & Weight (w/w \%) & Elements & Weight (w/w \%) \\
\hline $\mathrm{Cu}$ & 56.68 & $\mathrm{Ag}$ & 0.1 \\
\hline $\mathrm{Ca}$ & 1.61 & $\mathrm{Au}$ & 0.021 \\
\hline $\mathrm{Al}$ & 1.42 & $\mathrm{Pd}$ & 0.01 \\
\hline $\mathrm{Sn}$ & 1.40 & $\mathrm{Mn}$ & 0.005 \\
\hline $\mathrm{Fe}$ & 0.24 & Resin material & 38.29 \\
\hline $\mathrm{Zn}$ & 0.22 & & \\
\hline
\end{tabular}

Waste mobile phone PCBs (Fig. 1) used for this purpose were procured from the local market. After removing the mounted components of the PCBs with the help of screw drivers and other tools, the shredding was done by the metal cutter to cut it into small granules in the size range of 0.5 to $3.0 \mathrm{~mm}$ and the chemical analysis was done on ICP-OES (at NML Jamshedpur) as shown in Table 1. The laboratory reagents of 'AR' grade (Analytical grade) used in the experimental work was ammonium thiosulphate, copper sulfate, ammonium hydroxide, hydrochloric acid, nitric acid, potassium iodide, and potassium iodate.

\subsection{Leaching Procedure}

$15 \mathrm{~g}$ granules of the mobile PCBs sample were leached in the $250 \mathrm{ml}$ solution using $500 \mathrm{~mL}$ glass beaker which contained the pre-determined amount of the ammonium thiosulfate and copper sulfate at various $\mathrm{pH}$ values. All leaching experiments were carried out at an agitation speed of 250 rpm and room temperature $\left(\sim 25^{\circ} \mathrm{C}\right)$. A digital $\mathrm{pH}$ meter was used in all the experiments to monitor the $\mathrm{pH}$ values which were kept constant throughout the experiment by adding ammonia solution. The samples for the chemical analysis were withdrawn at every $0.5-1.0$ hour by a pipette and analysed by the atomic absorption spectrophotometer (Model: Solar S2). The gold and silver were analysed by the inductively coupled plasma optical emission spectrophotometer (ICP Model No. Varian Vista- MPX). After $8 \mathrm{~h}$ leaching the solution was removed and was filtered by the Whatmann 40 filter paper to separate the residual PCB from the solution. The residue was then dried in the vacuum oven for $2 \mathrm{~h}$ at $130^{\circ} \mathrm{C}$ to remove all the moisture from the sample and the samples were weighed and the weight of the residue was calculated.

\section{Results and Discussion}

To make the recovery of gold viable from the mobile PCBs by ammonium thiosulfate, it is required to optimise the leaching conditions. Various leaching parameters such as effect of concentrations of ammonium thiosulfate and copper sulphate, effect of $\mathrm{pH}$ and pulp density were studied and the results are presented below.

\subsection{Effect of Copper Sulfate}

As stated in Section 2, the presence of copper (II) ions promotes the dissolution of gold in the thiosulfate solution. Copper sulfate variation was carried out in the range of 0-48 $\mathrm{mM}$ at the conditions i.e. ammonium thiosulfate: $0.1 \mathrm{M}, \mathrm{pH}$ : $10-10.5$, pulp density: $60 \mathrm{~g} / \mathrm{L}$, temp: $25^{\circ} \mathrm{C}$, stirring speed: 250 $\mathrm{rpm}$ in $8 \mathrm{~h}$ time duration as shown in Fig. 3. It was observed from the figure that the presence of copper ions in the solution enhances the dissolution of gold with the formation of the copper (II)-amine complexes. While there was negligible gold recovery in the absence of copper sulfate, it has been found to increase up to $30 \%$ with the addition of $48 \mathrm{mM}$ copper sulfate. This can be attributed to the catalysing effect 
of copper sulfate present in the solution which enhances the dissolution of gold in thiosulfate system. Similar results have also been reported by some researchers ${ }^{7-9}$.

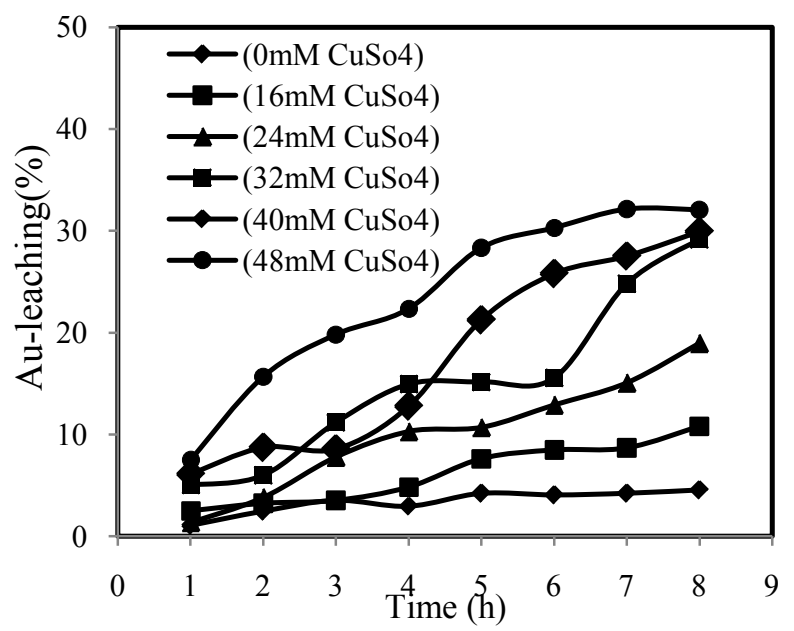

Figure 3. Effect of copper sulfate concentration on leaching of gold with time. [Ammonium thiosulfate : $0.1 \mathrm{M}, \mathrm{pH}: 10-10.5$, pulp density: $60 \mathrm{~g} / \mathrm{L}$, temp. : $25^{\circ} \mathrm{C}$, stirring speed: $\left.250 \mathrm{rpm}\right]$

\subsection{Effect of Ammonium Thiosulfate}

The variation in the ammonium thiosulfate concentration was made over a range of $0.05-0.25 \mathrm{M}$. The results are shown in the Fig 4. It is evident from the figure that maximum gold leached was $30.0 \%$ at the experimental conditions i.e. copper sulfate: $40 \mathrm{mM}, \mathrm{pH}$ : $10-10.5$, pulp density: $60 \mathrm{~g} / \mathrm{L}$, stirring speed: $250 \mathrm{rpm}$, temperature: $25^{\circ} \mathrm{C}$ in $8 \mathrm{~h}$ time duration. It is observed that the gold recovery increases up to $0.1 \mathrm{M}$ thiosulfate thereafter on further increase in thiosulfate concentration there is a decrease in the leaching of gold. This indicates that the higher thiosulfate concentration promotes the formation of unfavourable products such as trithionate, tetrathionate and polythionates ${ }^{10}$. Thus by maintaining a proper concentration of thiosulfate-ammonia in the system, maximum gold can be leached from the mobile PCBs in the presence of copper which acts as a catalytic agent in the solution ${ }^{5}$.

Copper was also analysed from different ammonium thiosulfate leach liquors. It was found during the experiment that higher thiosulfate concentration was accountable for more weight dissolution of PCBs mainly due to copper dissolution (Table 2). At $0.1 \mathrm{M}$ ammonium thiosulfate concentration maximum total weight dissolution was $2.70 \mathrm{~g}$ out of which the copper dissolution was $2.205 \mathrm{~g}$ which is a higher amount. At $0.05 \mathrm{M}$ and $0.25 \mathrm{M}$ thiosulfate, the copper dissolution was $0.103 \mathrm{~g}$ and $1.311 \mathrm{~g}$, respectively which also supports the maximum leaching of gold at $0.1 \mathrm{M}$ thiosulfate.

Table 2. Copper dissolution (at various thiosulfate concentrations)

\begin{tabular}{|c|c|}
\hline Ammonium thiosulfate conc. & Copper dissolution $(\mathrm{g})$ \\
\hline $0.05 \mathrm{M}$ & 0.103 \\
\hline $0.10 \mathrm{M}$ & 2.205 \\
\hline $0.25 \mathrm{M}$ & 1.311 \\
\hline
\end{tabular}

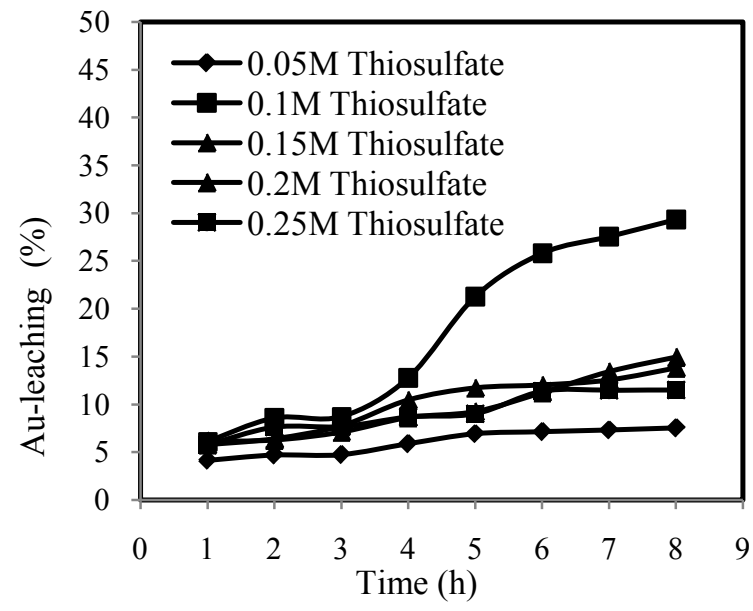

Figure. 4. Effect of ammonium thiosulfate concentration on leaching of gold with time, [Copper sulfate: $40 \mathrm{mM}, \mathrm{pH}$ : $10-10.5$, temp.: $25^{\circ} \mathrm{C}$, pulp density: $60 \mathrm{~g} / \mathrm{L}$, time: $8 \mathrm{~h}$, stirring speed: $250 \mathrm{rpm}$ ]

\subsection{Effect of pH Variation}

$\mathrm{pH}$ of the solution was varied in the range of 8-11. The results for leaching of gold are shown in the Fig. 5. With increase in $\mathrm{pH}$ from 8.0 the gold percentage also increases but after $\mathrm{pH} 10.5$ it shows decreasing trend. This shows that gold extraction occurs at very specific $\mathrm{pH}$ range i.e. $10-10.5^{11}$. The maximum gold was found to be $30.0 \%$ at $0.1 \mathrm{M}$ thiosulfate, $40 \mathrm{mM}$ copper sulfate, $60 \mathrm{~g} / \mathrm{L}$ pulp density, $25^{\circ} \mathrm{C}$ temperature in $8 \mathrm{~h}$ time duration. This can be explained with the fact that increasing the $\mathrm{pH}$ significantly increases the stability of $\mathrm{Cu}\left(\mathrm{NH}_{3}\right)_{4}{ }^{2+}$ and $\mathrm{Cu}\left(\mathrm{S}_{2} \mathrm{O}_{3}\right)_{3}{ }^{5-}$ ions resulting in increase in dissolution of gold in ammonium thiosulfate. However, at higher $\mathrm{pH}$ values, there is a decrease in the stability of $\mathrm{CuO}$ and $\mathrm{Cu}_{2} \mathrm{O}$ leading to removal of copper from the leach solution. This decreases the availability of copper responsible of dissolution of gold. Moreover, the precipitation of copper oxides on gold surface may also hinder its dissolution.

After each experiment carried out for the $\mathrm{pH}$ variation, the leach liquor obtained was chemically analysed for the ammonium thiosulfate concentration by the iodometric titration method. In the iodometric analysis, a solution containing one gram of potassium iodide, $10 \mathrm{~mL} \mathrm{HCl} \mathrm{(44g/L),} 25 \mathrm{~mL}$ potassium iodate $(3 \mathrm{~g} / \mathrm{L})$ was prepared and titrated with the thiosulphate leach liquor. Starch was used as indicator. The results shown in the Table 3 indicate that with increase in $\mathrm{pH}$ from $8.0-8.5$ to $10.0-10.5$, thiosulfate concentration also increases. This can be attributed to the maximum stability of thiosulfate in the $\mathrm{pH}$ range 10.0-10.5 (0.094 M). Further, at still higher $\mathrm{pH}$ of $10.5-11.0$, the thiosulfate concentration in the leach liquor was found to decrease $(0.086 \mathrm{M})$.

Table 3. Iodometric analysis of leach liquor at different $\mathrm{pH}$ ranges

\begin{tabular}{|c|c|}
\hline $\mathrm{pH}$ range & Thiosulfate conc. in leach liquor $(\mathrm{M})$ \\
\hline $8.0-8.5$ & 0.034 \\
\hline $9.0-9.5$ & 0.042 \\
\hline $10.0-10.5$ & 0.094 \\
\hline $10.5-11.0$ & 0.086 \\
\hline
\end{tabular}




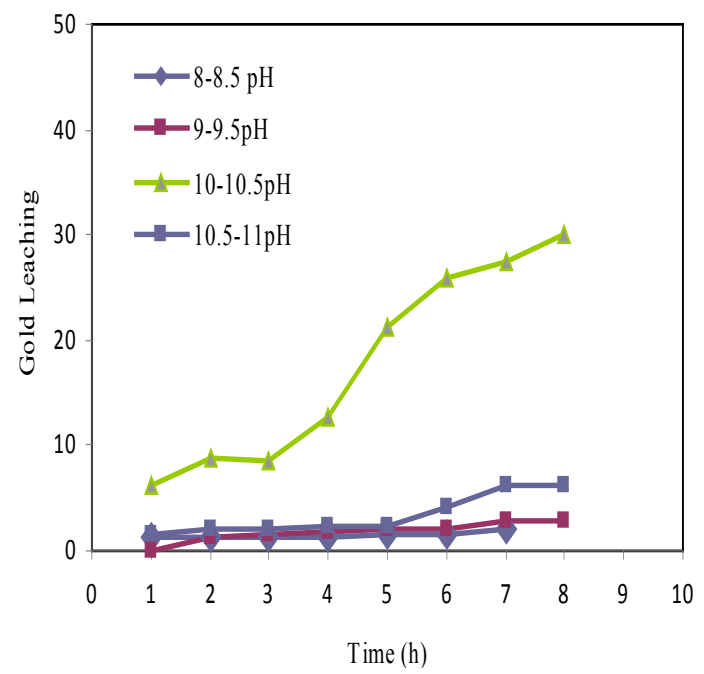

Figure 5. Effect of $\mathrm{pH}$ on leaching of gold with time [ammonium thiosulfate: $0.1 \mathrm{M}$, copper sulfate: $40 \mathrm{mM}, \mathrm{pH}: 10-10.5$, Temp: $\left.25^{\circ} \mathrm{C}\right]$

\subsection{Effect of Pulp Density}

The variation in the pulp density was done in the range of $10 \mathrm{~g} / \mathrm{L}-60 \mathrm{~g} / \mathrm{L}$ as shown in Fig. 6. It was observed from these experiments that the lower pulp density enhances the recovery of gold in the solution while at higher pulp density recovery percentage decreases. The maximum leaching was $56.7 \%$ gold at leaching conditions i.e. copper sulfate: $40 \mathrm{mM}$, ammonium thiosulfate: $0.1 \mathrm{M}, \mathrm{pH}: 10-10.5$, temperature: $25^{\circ} \mathrm{C}$, stirring speed: $250 \mathrm{rpm}$ in time $8 \mathrm{~h}$ at a pulp density of $10 \mathrm{~g} / \mathrm{L}$. The lower pulp density has been found to be beneficial on the recovery of gold due to availability of larger quantity of the reagent per unit weight of PCBs granules than that of higher pulp density ${ }^{12}$ leaching.

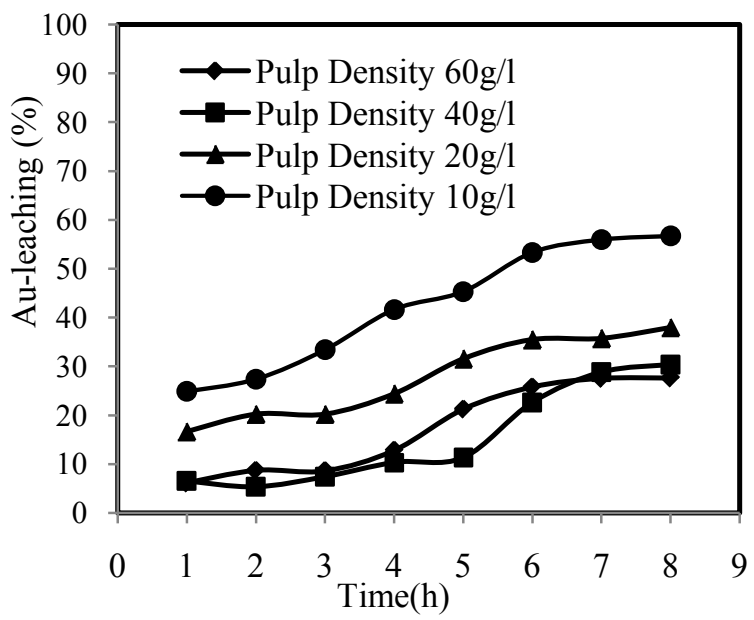

Figure 6. Effect of pulp density on leaching of gold with time [ammonium thiosulfate: $0.1 \mathrm{M}$, copper sulfate: $40 \mathrm{mM}, \mathrm{pH}: 10-10.5$, stirring speed: 250 rpm, Temp: $25^{\circ} \mathrm{C}$ ]

\subsection{Effect of Sample Varitaion}

Complete PCB leaching (whole unit) of the mobile phone was also done to observe its effect on the leaching of gold. Results are compared with the shredded PCBs granules as shown in Fig. 7. About $78.8 \%$ of gold was leached with a complete PCB while in case of shredded sample it was $30.35 \%$ with the same pulp density $(40 \mathrm{~g} / \mathrm{L})$ and other leaching variables. If the dissolution of copper is compared, it is observed as $1.53 \mathrm{~g} / \mathrm{L}$ and $11.8 \mathrm{~g} / \mathrm{L}$, respectively for complete PCB sample and its granules. The high dissolution of copper is mainly due to large surface area involved for the leaching of granules than that of complete unit itself. However, the large dissolution of copper results in higher losses of thiosulfate ions by its conversion to tetrathionate and other polythionates. Such ions are not helpful in the in the extraction of gold and thus there is decrease in the recovery in gold from shredded PCBs granules.

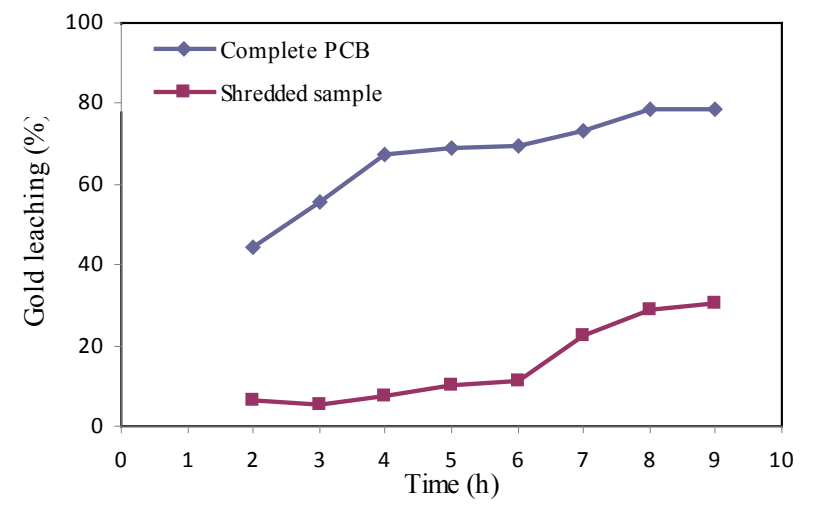

Figure 7. Comparison of gold leaching of complete PCB and PCBs granules for gold [Ammonium thiosulfate: $0.1 \mathrm{M}$, copper sulfate: $40 \mathrm{mM}$, $\mathrm{pH}: 10-10.5$, temp.: $25^{\circ} \mathrm{C}$, time: $8 \mathrm{~h}$, soild/liquid ratio: $\left.\sim 40 \mathrm{~g} / \mathrm{L}\right]$

\section{Conclusions}

Ammonium thiosulfate leaching of gold from waste mobile phones is an approach which has been tried to save the environment from the hazardous behaviour of the PCB metals as well as to recover the precious values of the PCB. On the basis of present study following conclusions can be drawn-

- The thiosulfate leaching of gold from waste PCBs exhibits that gold could be leached with good recovery under specific conditions. Recovery of gold was found to be highly dependent on the concentration of copper sulfate, ammonium thiosulfate, $\mathrm{pH}$ and pulp density.

- In the case of PCB granules, $56.7 \%$ gold could be leached under the optimised conditions viz., ammonium thiosulfate: $0.1 \mathrm{M}$, copper sulfate: $40 \mathrm{mM}$, pulp density: $10 \mathrm{~g} / \mathrm{L}, \mathrm{pH}: 10-10.5$, stirring speed: $250 \mathrm{rpm}$ at room temperature in $8 \mathrm{~h}$ time duration.

- In case of complete PCB unit the maximum gold leaching was $78.8 \%$ at thiosulfate: $0.1 \mathrm{M}$, copper sulfate: $40 \mathrm{mM}, \mathrm{pH}: 10-10.5$, stirring speed: $250 \mathrm{rpm}$ at room temperature in $8 \mathrm{~h}$ time duration.

\section{ACKNOWLEDGEMENTS}

The authors are thankful to the Director, CSIR-National Metallurgical Laboratory, Jamshedpur for giving permission 
to publish the paper. One of the authors (Abhishek Tripathi) is thankful to the Head, Dept. of Metallurgical Engineering, Institute of Technology, Banaras Hindu University, Varanasi for permitting him to do M. Tech. Dissertation work at CSIR-NML, Jamshedpur.

\section{REFERENCES}

[1] S. Schwazer, A. De Bongo G. Giuliani, S. Kluser, P. Peduzzi, January, 2005, A National Policy: Managing Waste to $2020-$ Submission, 1800 E-waste, Available:

[2] M. Schlnep, C. Hagelueken, R. Kuehrc, F. Magalinic, C. Maurer, C. Meskers, E. Mueller, F. Wang, Recycling from e-waste to resources, Report prepared by: Swiss Federal Laboratories for Materials Testing \& research, Umicore Precious Metals and United Nation, Printed by: Oktoberdruck AG, Berlin, Germany,July 2009, p.49.

[3] S. Orgul, U. Atalay, 2002 Reaction chemistry of gold leaching in thiourea solution for a Turkish gold ore. Hydrometallurgy, 67, 71-77.

[4] D. Zipperian, S. Raghavan, J. P. Wilson, 1988, Gold and silver extraction by ammoniacal thiosulfate leaching from a Rhyolite ore, Hydrometallurgy, 19, 361-375.
[5] C. Abbruzzese, P. Fornari, R. Massidda, F. Veglio, S. Ubaldini,1995, Thiosulfate leaching for gold Hydrometallurgy, 39, 265- 276 .

[6] M. G. Aylmore, D. M. Muir, 2001, Thiosulfate leaching of gold- a review, Miner. Eng. 14, 135-174.

[7] J. Ficeriova, P. Balaz, E. Boldizarova, S. Jelen, 2002. Thiosulfate leaching of gold from a mechanically activated $\mathrm{CuPbZn}$ concentrate, Hydrometallurgy, 67, 37-43.

[8] P. L. Breuer, M. I. Jeffrey, 2000, Thiosulfate leaching kinetics of gold in the presence of copper and ammonia, Miner. Eng., 13, 1071-1081.

[9] D. Feng, J.S.J. Van Deventer, 2006, Ammoniacal thiosulfate leaching of gold in the presence of pyrite, Hydrometallurgy, $82,126-132$.

[10] V. H. Ha, J. C. Lee, J. Jeong, H. T. Hai, M. K. Jha, Thiosulfate leaching of gold from waste mobile phones, Journal of Hazardous Material, 178, 1115 - 119.

[11] John O. Marsden, C. Iain House, 2006, Chemistry of Gold Extraction, Society of Mining, Metallurgy and Exploration, Inc. Colorado, USA12)

[12] P. Navarro, C. Vargas, A. Villarroel, F. J. Alguacil, 2002. On the use of ammoniacal/ammonium thiosulfate for gold extraction from a concentrate, Hydrometallurgy, 65, 37-42. http://www.grid.unep.ch/product/publication/download/ ewaste.en(pdf.). 